slab of both the Times Higher Education and the QS rankings, but are decoupled from real performance. Surveys contain data about opinions about performance, not data about performance. The link between effort, improvement, and ranking, essential to the virtuous circle, is broken. The same happens when the ranking position changes because of small shifts in methodology. Again, there is no coherent link between effort, performance, and ranking.

Wait, you might say, reputation matters to students. The value of degrees is affected by the pecking order. That is right. And a reputational hierarchy based on surveys, by itself, uncontaminated by other factors, does tell us something important. But a reputational ranking alone, while interesting, cannot drive continually improving performance in real terms. It can only drive a position-and-marketing game. In the end, reputation must be grounded in real performance to consistently benefit stakeholders and the public good.

The point can be made by analogy. The winner of the World Cup in football is determined by who scores the most goals within the allotted time on the field. Now what if FIFA changes the rules? Instead of rewarding the final performance alone, who scores the most goals, it decides to give 50 percent to the most goals, and 50 percent to the team believed to be the best, measured by survey. We would all have less trust in the result, wouldn't we?

Multi-indicator rankings provide a large data set, but because the link between effort in each area and the rankings outcome is not transparent, they cannot coherently drive performance. The incentives pull in different directions and the effects are invisible. In ARWU, the different indicators correlate fairly well; they pull in the same direction and share common performance drivers. But QS and Times Higher Education use heterogeneous indicators.

On the other hand, if the multi-indicator rankings were disaggregated, the individual indicators could effectively drive performance improvement. Then, at least, ranking competition would be directed towards better outcomes, not reputation for its own sake.

DOI: http://dx.doi/org/ı0.60I7/ihe.20I7.89.9762

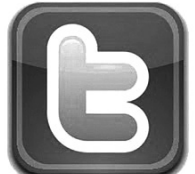

In addition to our Web site and Facebook page, we are now tweeting. We hope you will consider "following" us on Twitter!

\section{Pursuing Rankings in the Age of Massification: For Most-Forget About It}

\section{Philip G. Altbach and Ellen Hazelkorn}

Philip G. Altbach is research professor and founding director of the Center for International Higher Education at Boston College, US. E-mail: altbach@bc.edu. Ellen Hazelkorn is policy advisor to the Higher Education Authority (Ireland), and emerita professor and director, Higher Education Policy Research Unit (HEPRU), Dublin Institute of Technology, Ireland. E-mail: Ellen.hazelkorn@dit.ie.Insights from M. Yudkevich, P. Altbach, and L. Rumbley, eds. The Global Rankings Game (Routledge 2016) and E. Hazelkorn, ed. Global Rankings and the Geopolitics of Higher Education (Routledge 2016) inform this article.

$\mathrm{W}$ e have one simple argument: universities around the world, many more than will ever publicly admit it, are currently obsessed with gaining status in one or more national or global rankings of universities. They should quit now.

Although some may succeed in becoming ranked or may improve their numerical scores marginally, it is almost never worth either the resources required, or the substantial changes in mission or academic programs necessary. Indeed, most "gains" are due to methodological changes, introduced by the various rankings to remain in the media and public headlines, and thus commercially lucrative.

Our advice is particularly pertinent for midrange national, regional, and specialist universities and colleges, and their stakeholders and governments. Today, these institutions constitute the overwhelming majority of higher education institutions (HEIs) worldwide, due to a combination of demographic demand for participation in higher education, and societal and economic requirements for a more highly educated citizenship. Indeed, projections suggest the number of students enrolled in higher education is forecast to rise from 99.4 million in 2000 to $4 \mathrm{I} 4.2$ million in 2030, an increase of 316 percent. Accommodating these additional students will require more than four major universities (30,000 students) to open every week for the next fifteen years.

These HEIs are the real backbone of society and their locales. They serve as the anchor institution, the mainstay for social and economic growth and development. They will develop some research focus, but are unlikely to become globally prominent.

However, our advice extends even to those universities that adopt the mantle of "flagship"- those at the top of the hierarchy in their country or state. This is because rank- 
ings pervert one of the main purposes of higher education, which is to ensure that students and graduates acquire the knowledge and skills needed for a successful, satisfying, and active life throughout one's increasingly longer life span.

\section{What Global Rankings Measure-and Don't Measure}

It is by now well-known that the three main global rankings: Academic Rankings of World Universities (ARWU, the Shanghai Rankings), Times Higher Education (THE) rankings, and QS, mainly assess two things: research productivity and (except for ARWU) reputation among peers, employers, and students. THE devotes 90 percent and QS 70 percent to measuring research, while, respectively, they assign 33 percent and 50 percent to reputation. THE uses a subjective reputational survey to measure teaching quality, but it is unclear how anyone can rate teaching ability without being in the classroom. Internationalization incentivizes quantity over quality, and often reflects a country's geographic position. Switzerland is one good example.

U-Multirank, developed by the European Union, uses a broader set of indicators but has struggled to gain wide acceptance, while others, such as the Leiden Rankings, are more narrowly focused in scope and coverage.

There are a growing number of national and specialist versions, ranging from those done by such publications as US News and World Report in the United States, Macleans in Canada, Der Spiegel in Germany, the Asahi Shimbun in Japan, to Global MBA Rankings from the Financial Times and the Green Metric World University Ranking from Indonesia. The former have access to a broader dataset, but they all suffer from methodological problems.

\section{Why Universities Should Forget About Rankings}

There are I8,000 HEIs worldwide, according to the World Higher Education Database (http://www.whed.net/home. php). However, only a small minority will ever appear in the rankings, no matter how much they try and how many resources are devoted to the task. Indeed, the top roo universities represent only 0.5 percent of HEIs or 0.4 percent of students worldwide. No doubt being ranked is itself an accomplishment, but maintaining position and even climbing in the rankings is not easy. There are rising expectations, and slippage is a constant problem-bringing inevitable negative publicity.

This is because competition is fierce, and those in the upper reaches of the rankings have considerable resources, financial and human, to devote to the effort. Furthermore, rankings favor universities with strength in the sciences, engineering, and medicine. Newer and smaller universities, especially in developing economies, and institutions without these specializations, have limited opportunities.
At the same time, universities already at the top of the rankings continue to improve. Thus, without massive financial and other resources, it is almost impossible for academic institutions to improve their ranking status.

\section{LESSONS FROM RAN KINGS}

Rankings have had an outsized impact on higher education and policy. International evidence from the last decade and more show how they influence decision-making, academic behavior, and resource allocation; research priorities and disciplinary practices, including publication in Englishlanguage and internationally ranked journals; recruitment and promotional criteria; and organizational structures and institutional mergers. Today, many universities have a rankings strategy and institutional research units that benchmark rankings performance.

\section{However, our advice extends even to those universities that adopt the mantle of "flagship" - those at the top of the hi- erarchy in their country or state.}

Because of the overemphasis on research, international experience highlights emergent tensions between a university's mission and values, and efforts to enter and/or climb in the rankings. Teaching and undergraduate students, as well as the arts, humanities and social sciences, often take a backseat when decisions are made or resources are allocated. Some universities report preferential attention and benefit being given to research "stars" over longer-employed or domestic faculty. Other examples show how universities have attempted to refocus student entry criteria and become more selective and exclusive to better meet outcome indicators such as completion rates, graduate employment or salary levels, alumni donations, etc. However, in making such changes, universities can significantly alter their mission and purpose. Other examples highlight the huge financial costs associated with attempting to make statistically insignificant changes in their ranked order-leading to huge debt.

\section{Focus on Mission, Not Rankings}

Our combined recent experiences highlight the fact that rankings have become a major factor influencing all higher education. Even Yale University recently announced it can no longer ignore them. Although in the midst of a war zone, a university recently approached one of the authors, 
because it was concerned about its position in the rankings. This experience is not unique. At a time when universities seek to promote and protect academic autonomy from all kinds of interference, it is remarkable that some universities willingly allow their decisions to become vulnerable to an agenda set by others.

Prestige and reputation have become dominant drivers rather than pursuance of quality and student achievement, intensifying social stratification and reputational differentiation. There is a big assumption that the choice of indicators and associated weightings are meaningful measures, but there is no international research evidence that this is true.

The problem is particularly acute-and concerningfor the overwhelming majority of middle- and lower-ranked universities and colleges that have got caught up in the rankings maelstrom. To these universities, and their governments, we say: concentrate on what matters-helping the majority of students earn credentials for sustainable living and employment, rather than ensuring that your institution matches criteria established by different rankings. Even if much attention and resources are so expended, the results will not be favorable.

DOI: http://dx.doi/org/ıo.6oI7/ihe.20I7.89.9759

\section{The American Academic Profession at Risk}

\section{MARTIN J. Fin KELSTEIN}

Martin Finkelstein is professor of higher education at Seton Hall University, US. E-mail: Martin.Finkelstein@shu.edu.

$\mathrm{O}$ ver the past half century, the United States emerged arguably as the world's premier national system of higher education in terms of both size and quality. China, of course, now surpasses the United States in total student enrollments and produces more PhDs annually. It counts as well a larger number of instructional staff than the United States. India is on the verge of surpassing the United States in size, at least in terms of total student enrollments. American claims to quality remain—claims, however, that are increasingly at risk.

\section{A New Appraisal}

That is the argument of a new, elaborately detailed analysis of the status and prospects of the American academic profession: The Faculty Factor, by Martin Finkelstein, Valerie

Conley, and Jack Schuster (Johns Hopkins University Press, October 20I6). Building on already disturbing indicators of deterioration reported in our earlier book in the first years of the twenty-first century (Schuster and Finkelstein, The American Faculty, 2006), our new book creatively mines fresh-and heretofore unavailable-data sources to follow the fortunes of the American faculty through the lingering Great Global Recession of 2008 .

For those who are not experiencing the American system on a daily basis, it provides a sharp, albeit nuanced, corrective to perceptions of the ideal, typical American model of academic work and careers that emerged from Christopher Jencks and David Reisman's The Academic Revolution (1968), Bowen and Schuster's American Professors (1986), and even Burton Clark's Academic Life (ig87). That model was built on the concept of shared governance, stewardship of the institutions' academic mission, including supreme faculty authority in academic matters, especially personnel issues of hiring and promotion; on the concept of tenure, which protected academic freedom, served as a magnet for scholars around the world, and regularized the structure of an academic career (including a six-to-seven year probationary period, followed by a high stakes "up or out" evaluation, leading to a continuous appointment and a relatively stable career); and the concept of an integrated academic role, that included teaching, research (often broadly defined), and service in a mutually reinforcing, synergistic dynamic, with each functional role seen as strengthening the others.

\section{By the Numbers: A New Model}

The "new" model of academic work and careers in the United States is built on an increasingly contingent, stratified academic workforce; the unbundling of the traditionally integrated role into specialist teaching, research, and administrative roles; and the progressive yielding of faculty authority on campus, even in academic matters, to a growing core of full-time professional administrators. About 35 percent of the headcount of instructional staff are full-time, tenured faculty, or faculty on tenure tracks; about 50 percent now work part-time (predominantly teaching one to two courses on an ad hoc basis); and the remaining I5 percent are in full-time fixed contract positions, which are focused on teaching only, research only, or program administration only (with no expectation of service, including participation in governance). With explosive growth in the general, but also academic, administrative ranks, decisions about academic programs and policies are increasingly made by administrators rather than faculty, and faculty's sphere of influence has progressively shrunk down to the department and even program levels.

Our major findings reveal that for the past generation, nearly three-fifths of new hires into faculty positions have 